\title{
Effect of Furrow Irrigation on the Severity of False Smut in Susceptible Rice Varieties
}

\author{
Steven A. Brooks, United States Department of Agriculture-Agricultural Research Service (USDA-ARS), Dale \\ Bumpers National Rice Research Center, Stuttgart, AR 72160; Merle M. Anders, University of Arkansas, Rice Re- \\ search and Extension Center, Stuttgart, AR 72160; and Kathleen M. Yeater, USDA-ARS SPA, College Station, TX \\ 77845
}

\begin{abstract}
Brooks, S. A., Anders, M. M., and Yeater, K. M. 2010. Effect of furrow irrigation on the severity of false smut in susceptible rice varieties. Plant Dis. 94:570-574.

False smut (Ustilaginoidea virens) is an important emerging disease of rice (Oryza sativa) in the southern United States, where all major rice cultivars and hybrids are susceptible to the disease. False smut susceptibility was evaluated in traditional paddy-rice fields and under furrowirrigated conditions to determine the effects of alternative agricultural practices on the severity of this disease. Highly effective false smut suppression was observed in furrow-irrigated rice, where the disease was nearly eliminated in susceptible rice entries. False smut suppression was observed for two hybrids and one conventional rice cultivar, demonstrating that suppression was not limited to specific germplasm sources. Kernel smut severity was also monitored, but no effect on this disease was observed from the irrigation treatments. Therefore, suppression of disease severity in nonflooded rice appears to be a phenomenon unique to the rice-false smut pathosystem, which can be exploited to achieve effective field resistance to this disease.
\end{abstract}

False smut (Ustilaginoidea virens (Cooke) Takah.) is an important emerging disease of rice (Oryza sativa L.) in the United States. Historically an uncommon disease, false smut has recently increased in importance throughout the rice growing regions of the world $(11,12,14,16)$. In Arkansas, the largest rice producing state in the United States, the disease was first recorded in 1997 (3). Since the late 1990s, false smut has become an increasing concern, especially in years where a significant portion of the crop has been planted later than normal. In some cases, growers have become concerned about yield loss, particularly when disease severity has been high in favorable years. However, accurate measurements of statewide yield losses have not been obtained to date.

The increasing frequency of false smut in U.S. rice has prompted a need to develop management strategies for this dis-

Corresponding author: S. A. Brooks

E-mail: ricegenes@mac.com

Mention of a trademark of a proprietary product does not constitute a guarantee or warranty of the product by the United States Department of Agriculture, and does not imply its approval to the exclusion of other products that may also be suitable.

Accepted for publication 6 January 2010.

doi:10.1094/PDIS-94-5-0570

This article is in the public domain and not copyrightable. It may be freely reprinted with customary crediting of the source. The American Phytopathological Society, 2010. ease. Currently, all major rice varieties grown in the southern United States are susceptible to false smut (13), and the dominant rice cultivation system (in rotation with soybean, on tilled soil, with high fertilizer input) promotes the greatest severity of this disease (2). This combination of factors serves only to promote the potential for disease epidemics in the future. Since resistance to false smut is not known (8) and variety development is a process that takes decades, short-term disease control strategies are necessary to mitigate crop losses in the near future.

It is known that nitrogen fertilizer inputs positively influence the severity of false smut (5). Recently, we reported similar findings from a long-term crop rotation study, and discovered that a balance between effective disease control and maximum yield was attainable at moderate nitrogen fertilizer rates (2). However, changing the status quo as a measure to prevent disease epidemics can prove challenging. A single disease problem will not be the stimulus to adopt new production practices unless its impact is catastrophic. Rice farmers seek to maximize yield, and reducing fertilizer application is counter intuitive to that goal.

Of all the foreseeable changes in rice production in Arkansas, water availability is likely to be the most prominent. As recently as 1991, the Arkansas Natural Resources Commission declared several counties as "Critical Ground Water Areas" (6). Since that time, two more areas have received the same designation. This designation indicates water is being drawn from the alluvial aquifer at a faster rate than it is recharged. T. B. Reed (10) reported that continued groundwater use at the 1997 rate was unsustainable. If rice production is to continue in these areas, it will need to be done with significantly less water.

Furrow irrigation is one method in which rice can be produced with substantial water savings over flooded rice paddies. This system of rice production is identical to some methods used for production of soybean, which is commonly grown in rotation with rice and is reported to use 50 to $60 \%$ less irrigation water than contour levee systems used in rice culture (15). In addition, furrow-irrigated rice has the potential to reduce methane gas emissions when compared to flooded rice paddies that contribute significantly to atmospheric methane $(1,4)$. Production input costs are also reduced as levee construction is eliminated, and application of fertilizer and chemicals can be performed with ground equipment instead of aerial application. Combined with a tail water recovery system, furrow irrigation can save water, reduce greenhouse gas emissions, and reduce waterway pollution from runoff and aerial drift.

Furrow-irrigated rice cultivation is not without challenges, and the greatest deterrent is reduced yield in aerobic soil conditions. Significant yield penalties have been observed for furrow-irrigated rice in Arkansas (M. Anders, unpublished results); however, economic analyses of net returns after cost savings were not calculated. Therefore, yield penalties can be misleading, as the net return will be balanced by significant cost savings. Although furrowirrigated rice occupies $<1 \%$ of Arkansas rice acreage (15), projected irrigation water shortages (6) may prompt the increase of acres in the state.

Previously (2), we demonstrated that conservation tillage, a sustainable agricultural practice, effectively reduced losses from false smut in conventionally grown paddy rice. Herein, our primary objective was to determine the effect of furrow irrigation on false smut severity in susceptible rice varieties, to support our long-term goal to resolve the effects of alternative (sustainable) rice culture practices on important diseases of rice. To address our objective, we evaluated false smut severity in three field experiments conducted over 3 
years. We selected modern rice varieties that were relevant to rice production in Arkansas. The presented work resolves the effects of fertility, alternative irrigation, and disease resistance on smut severity in rice.

\section{MATERIALS AND METHODS}

Study location. The two experimental sites were located at the University of Arkansas Rice Research and Extension Center in Stuttgart (N 34 $27^{\prime}$ lat; W 91 $24^{\prime}$ long). The sites are situated within the Grand Prairie region of eastern Arkansas, where natural infestation of grain smuts is known (2), and the Dewitt silt loam (fine, smectitic, thermic, Typic Albaqualf) soil is representative of the region (9).

Plant materials. Seed of rice hybrids 'CLXL 730' and 'CLXL 729' were provided by RiceTec (Alvin, TX). Seed of rice cultivar 'CL161' was provided by Horizon Ag (Memphis, TN). Hybrids were selected due to superior performance in aerobic soil conditions relative to conventional cultivars (M. Anders, unpublished results), known susceptibility to false smut, and resistance to kernel smut (2). CL161 was included as a conventional cultivar control with susceptibility to false smut and kernel smut (13). All three entries were Clearfield varieties, and resistant to the herbicide Newpath (BASF Agricultural Products, Research Triangle Park, NC) used for red rice weed control.

Field preparation for furrow irrigation. Fields were prepared by tilling once with a standard disk at the end of the previous crop season. In the spring, the field was disked again followed by two passes with a triple-K (light field cultivator). Beds were formed using a 6.4-m bedder (Eddins Manufacturing Inc., Stuttgart, AR) with furrow coulters placed at $76-\mathrm{cm}$ intervals. The formed beds were $10 \mathrm{~cm}$ above the furrow bottoms. Hybrid rice was drill seeded at $39 \mathrm{~kg} \mathrm{ha}^{-1}$ on the beds and in furrows using an Almaco no-till drill (Almaco, Nevada, IA) with a $19-\mathrm{cm}$ row spacing. Irrigation to maintain aerobic soil conditions was carried out by running water down the furrows until the beds had wetted to the center. Watering was carried out weekly until the plants reached panicle initiation, after which watering was increased to twice weekly. Furrow irrigation maintained aerobic soil conditions throughout the growing season, as a flood was not established in any part of the fields.

Irrigation study (2006 to 2008). On 23 May 2006, 10 April 2007, and 21 April 2008, four replications were planted into a split-block design. Main plots were crop rotation (continuous rice, rice-soybean), and irrigation treatments (flooded, furrowirrigated) were $6 \times 45 \mathrm{~m}$ subplots. Seed of rice hybrid CLXL 730 was used in 2006, while CLXL 729 (RiceTec) was used in 2007 and 2008. All plots were fertilized with $\left(112 \mathrm{~kg} \mathrm{~N} \mathrm{ha}^{-1}+45 \mathrm{~kg} \mathrm{P}_{2} \mathrm{O}_{5} \mathrm{ha}^{-1}+67\right.$ $\mathrm{kg} \mathrm{K}_{2} \mathrm{O}$ ha $^{-1}$ ) using Agrotain (Agrotain International, L.L.C.) coated urea pellets (46-0-0), triple super phosphate (0-46-0), and muriate of potash (0-0-60). $\mathrm{P}$ and $\mathrm{K}$ were applied prior to planting and $\mathrm{N}$ was applied postemergence, at the four- to fiveleaf growth stage to a dry soil surface. Immediately following the $\mathrm{N}$ application, all irrigation treatments were applied. Flooded plots were kept in a 10 -cm flood until draining for harvest, while furrowirrigated plots were watered as previously described. All plots were harvested with a John Deere 45 combine (Deere \& Company, Moline, IL) retrofitted with a Carter weigh bucket (Carter Mfg. Co. Inc., Brookston, IN) at approximately $18 \%$ moisture for yield measurements. Grain samples for moisture determinations and disease evaluations were collected from the combine at harvest. Grain yields were adjusted to and reported at $12 \%$ moisture.

Analyses of all dependent variables were performed using the GLIMMIX procedure in SAS (version 9.1.3). False smut and kernel smut were lognormally distributed. This probability distribution was specified in the model after the variable(s) was coded by adding $(+1)$ to each value. Yield followed a Gaussian (normal) distribution. Crop rotation, irrigation, and their interaction were considered fixed effects in the statistical model(s). The appropriate error terms and degrees of freedom based upon the experimental design were incorporated. Rice hybrid varieties were considered as random effects to infer the range of rice varieties as we were not implicitly focused on the means results of the specific varieties included in this study. Estimation of variability in rice varieties is presented through best linear unbiased predictors (BLUPs) and predicted standard error as calculated using the SOLUTIONS option. Estimated means, standard errors, and differences of means in the fixed effects were calculated using the LSMEANS option.

Nitrogen source study (2006 to 2007). On 23 May 2006 and 10 April 2007, four replications of a split-plot randomized complete block design were planted into a study containing two irrigation treatments (flooded, furrow-irrigated), and four $\mathrm{N}$ source treatments (Urea, Agrotain coated urea, sulfur coated urea [Agrotain International, L.L.C.], and a nonfertilized control treatment). The two coatings reduce $\mathrm{N}$ loss from the soil due to volatilization. The rice variety CLXL 730 was used in 2006 and CLXL 729 in 2007. Apart from the N treatments, all plots were managed as previously described. At the four- to five-leaf growth stage, $\mathrm{N}$ source treatments were applied to a dry soil surface in all plots at a rate of $112 \mathrm{~kg} \mathrm{~N} \mathrm{ha}^{-1}$. Harvesting was done as described in the previous study.

Analyses of all dependent variables were performed using the GLIMMIX pro- cedure in SAS (version 9.1.3). False smut and kernel smut were lognormally distributed. This probability distribution was specified in the model after the variable(s) was coded by adding $(+1)$ to each value. Yield followed a Gaussian (normal) distribution. Irrigation, $\mathrm{N}$ source, and their interaction were considered fixed effects in the statistical model(s). The appropriate error terms and degrees of freedom based upon the experimental design were incorporated. Estimated means, standard errors, and differences of means in the fixed effects were calculated using the LSMEANS option.

Smut nursery experiment (2008). The smut disease nursery was located in a field known to have natural infestation of false smut and kernel smut in the previous rice crop (2007; S. A. Brooks, unpublished results). The field was divided into two sections of approximately $30 \times 43 \mathrm{~m}$ each, where soil preparation and preplant $\mathrm{P}$ and $\mathrm{K}$ applications were the same as above. Due to irrigation constraints at the site, only a single comparison (replication) of flood versus furrow irrigation could be made. Each section was planted on 6 May with two rice varieties (CLXL 729 and CL161; $15 \times 43 \mathrm{~m}$ each variety per section), where the hybrid seeding rate and row spacing were the same as above. The seeding rate for CL161 was $101 \mathrm{~kg} \mathrm{ha}^{-1}$, which is a typical seeding rate for a conventional cultivar. A single excessive nitrogen fertilizer application of $246 \mathrm{~kg} \mathrm{~N} \mathrm{ha}^{-1}$ was made with Agrotain (Agrotain International, L.L.C.) coated urea pellets (46-0-0), and applied as a pre-irrigation treatment at the four- to five-leaf seedling growth stage. This $\mathrm{N}$ rate was previously shown to promote smut diseases (2). Precision leveling of the ground (no slope) at this site made it difficult to furrow irrigate the rice beds. Therefore, the furrow-irrigated section was flushed once a week by holding water on the beds with a levee, and then dropping the standing water within $18 \mathrm{~h}$. This process maintained aerobic soil conditions in the section. In the flooded section, $10 \mathrm{~cm}$ of water was established in the plot and maintained throughout the season. Infected rice grain was collected at harvest from four subsamples $\left(37 \mathrm{~m}^{2}\right.$ each) per variety plot with a combine (as above), with the exception of CL161 from the flooded section. The CL161-flood plot lodged severely from the wind and rain of hurricanes Gustav and Ike in August and September of 2008. Therefore, the rice that could be picked up by the combine was harvested as a single sample from the entire plot.

Sampling and disease rating. False smut and kernel smut (Neovossia horrida (Takah.) Padwick \& A. Khan. Syn. Tilletia barclayana (Bref.) Sacc. \& P. Syd.) disease ratings were performed according to Brooks et al. (2). Briefly, false smut sori were recovered by hand sieve from 1 to 1.5 
$\mathrm{kg}$ grain plot-samples, and disease severity was reported as sori number per $\mathrm{kg}$ seed harvested. Subsequently, four 50-g subsamples of seed were used to rate kernel smut severity. Each subsample was soaked overnight in $0.27 \mathrm{M} \mathrm{KOH}$ to clear the hulls (palea and lemma; 7), and smutted kernels were identified visually over a light box. Kernel smut severity was reported as the number of symptomatic kernels per $\mathrm{kg}$ of seed harvested. Herein, disease severity is reported as least squared means (LSM) of $\log$ transformed severity values.

Canopy microclimate measurements. Canopy temperature and relative humidity were recorded for comparison of microclimates in flooded and furrow-irrigated plots within the 2008 smut nursery. Sensors that measure both temperature and relative humidity (Model HMP45C, Campbell Scientific, Inc., Logan, UT) were placed within the canopy of rice entry CLXL 729 from 28 July through 17 August 2008. This timeframe encompassed panicle emergence (heading) through grain fill for all entries and treatments. The vertical placement of the sensors was at the point of flag leaf attachment to the culm. Both sensors were connected to a CR800 Datalogger (Campbell Scientific), which was set to record maximum, minimum, and average values on a per minute basis. Analysis of microclimate data was performed using Microsoft Excel 2004 for Mac (Version 11.5.4, Microsoft Corporation, Redmond, WA) and LoggerNet 3.4.1 (Campbell Scientific).

\section{RESULTS}

False smut: irrigation $\times$ rotation $(2006$ to 2008). False smut severity was evaluated from 2006 through 2008 in a rice irrigation and crop rotation experiment. Irrigation $(P<0.0192)$ was the only significant treatment, and there were no interactions between the treatments (Table 1). Disease severity in furrow-irrigated conditions was negligible and was consistently less than the severity detected in the

Table 1. Summary of analysis of variance probability values for fixed effects on smut severity (number of infected kernels per kilogram of harvested seed) and grain yield from a combined analysis of studies conducted in 2006, 2007, and 2008 at the University of Arkansas Rice Research and Extension Center, Stuttgart, AR

\begin{tabular}{lccc}
\hline & \multicolumn{3}{c}{$\boldsymbol{P}>\boldsymbol{F}$} \\
\cline { 2 - 4 } Treatment $^{\mathbf{a}}$ & False smut & Kernel smut & Yield \\
\hline Irrigation-rotation & 0.0192 & 0.3649 & 0.0032 \\
$\quad$ Irrigation & 0.3060 & 0.3447 & 0.4679 \\
Rotation & 0.1204 & 0.7405 & 0.3092 \\
$\quad$ Irrigation-rotation & 0.0289 & 0.4640 & 0.0219 \\
Irrigation-nitrogen source & 0.0048 & 0.6543 & $<0.0001$ \\
$\quad$ Irrigation & 0.0057 & 0.4549 & 0.1811 \\
$\quad$ Nitrogen source & & \\
Irrigation-nitrogen source &
\end{tabular}

${ }^{\text {a }}$ Irrigation-rotation $=2006$ to 2008 irrigation-rotation experiments and irrigation-nitrogen source $=$ 2006 and 2007 irrigation-nitrogen source experiments.

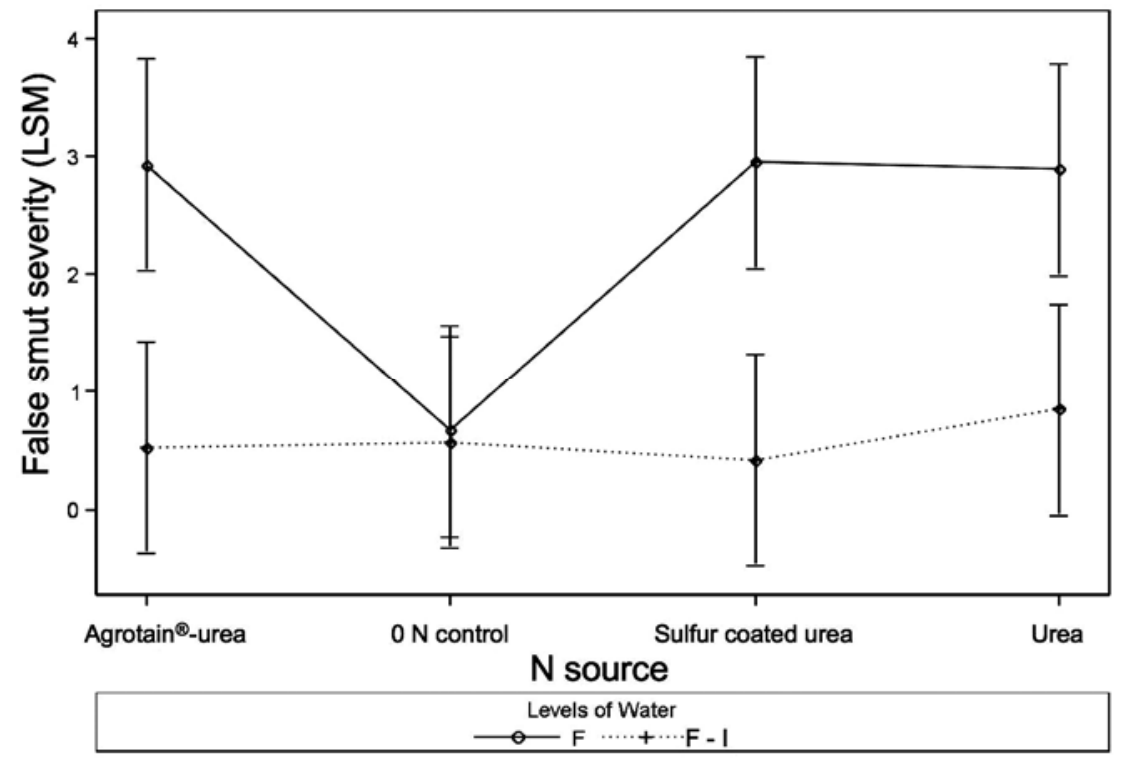

Fig. 1. Least squared means (LSM) for irrigation-N source, sliced by water; $95 \%$ confidence level. False smut severity (LSM, Y-axis) plotted with N source (X-axis; Agrotain-urea, nonfertilized control, sulfur-coated urea, and urea). Solid line represents values from flooded (F) conditions, and dashed line represents values from furrow-irrigated (FI) conditions. flooded plots ( 0.5625 versus 2.3779 LSM, respectively). Covariance parameter estimates were calculated and the variance due to random effects in the model was assessed (not shown). Variance due to the year effect was high compared to the remaining random effects and accounted for $35.7 \%$ of total model variance. Year-toyear estimates of variability to the mean (BLUPs, 0.4975, 0.3526, and -0.8501 for years 2006, 2007, and 2008, respectively) indicated a decline in false smut severity over the course of the study. Grain yields were also monitored over the course of the study $(10,159$ and $7,177 \mathrm{~kg} / \mathrm{ha}$ flooded and furrow-irrigated treatments, respectively). Irrigation $(P<0.0032)$ was the only significant treatment, and there were no interactions between treatments (Table 1).

False smut: nitrogen source (2006 to 2007). False smut severity was evaluated in the 2006 to 2007 nitrogen source experiments. Irrigation $(P<0.0289)$ and $\mathrm{N}$ source $(P<0.0048)$ were both significant treatments, and there was a significant irrigation $\times \mathrm{N}$ source interaction $(P<$ 0.0057; Table 1). The inclusion of nonfertilized control plots resulted in $\mathrm{N}$ source being a significant treatment in the model. This also caused the interaction between treatments. Figure 1 illustrates false smut severity among $\mathrm{N}$ source treatments in flooded and furrow-irrigated plots. The zero $\mathrm{N}$ treatment (rate) had significantly less false smut (0.6713-0 LSM) than the remaining flooded rice treatments, which produced highly similar disease severity values (2.9295-AG, 2.9539-SR, and 2.8896-U LSM values). Therefore, $\mathrm{N}$ rate was the significant factor detected in the analysis as a source. As in the irrigation study, disease severity in furrow-irrigated conditions was negligible and significantly less than the flooded plots $(0.5906$ versus 2.3611 LSM, respectively). Nitrogen source was not significant in furrowirrigated plots as $\mathrm{N}$ treatments were not different (0.5246-AG, 0.4220-SR, and 0.8468 -U LSM values), and did not increase disease severity above zero $\mathrm{N}$ (0.5690-0 LSM). However, grain yields were affected by $\mathrm{N}$ rate in furrow-irrigated plots (2932-0, 7127-AG, 7379-SR, and $7430-\mathrm{U} \mathrm{kg} / \mathrm{ha}$ ). The effect of $\mathrm{N}$ rate (via the inclusion of a zero $\mathrm{N}$ control) on false smut severity in flooded rice, but not in furrow-irrigated conditions, resulted in the significant irrigation $\times \mathrm{N}$ source interaction.

Kernel smut: irrigation $\times$ rotation (2006 to 2008) and nitrogen source (2006 to 2007). Kernel smut severity was evaluated in both the irrigation (2006 to 2008) and the N source studies (2006 to 2007). No treatments (irrigation, rotation, or $\mathrm{N}$ source/rate) significantly affected disease severity (Table 1), which showed stability in the hybrid varieties' resistance across all treatments. This resistance was evident in the low disease severity values in each 
study (irrigation study: 0.5647 -furrowirrigated and 0.8536-flooded LSM values; $\mathrm{N}$ source study: 0.2429-furrow-irrigated and 0.4052-flooded LSM values). In contrast to false smut, variance due to year for kernel smut severity was low in both studies and represented only 5.6 and $13.1 \%$ of the total experimental variance for the irrigation and $\mathrm{N}$ source studies, respectively.

CLXL 729 and CL161 evaluation (2008). In 2008, observations of both smut diseases were made for the conventional cultivar CL161 in addition to the hybrid

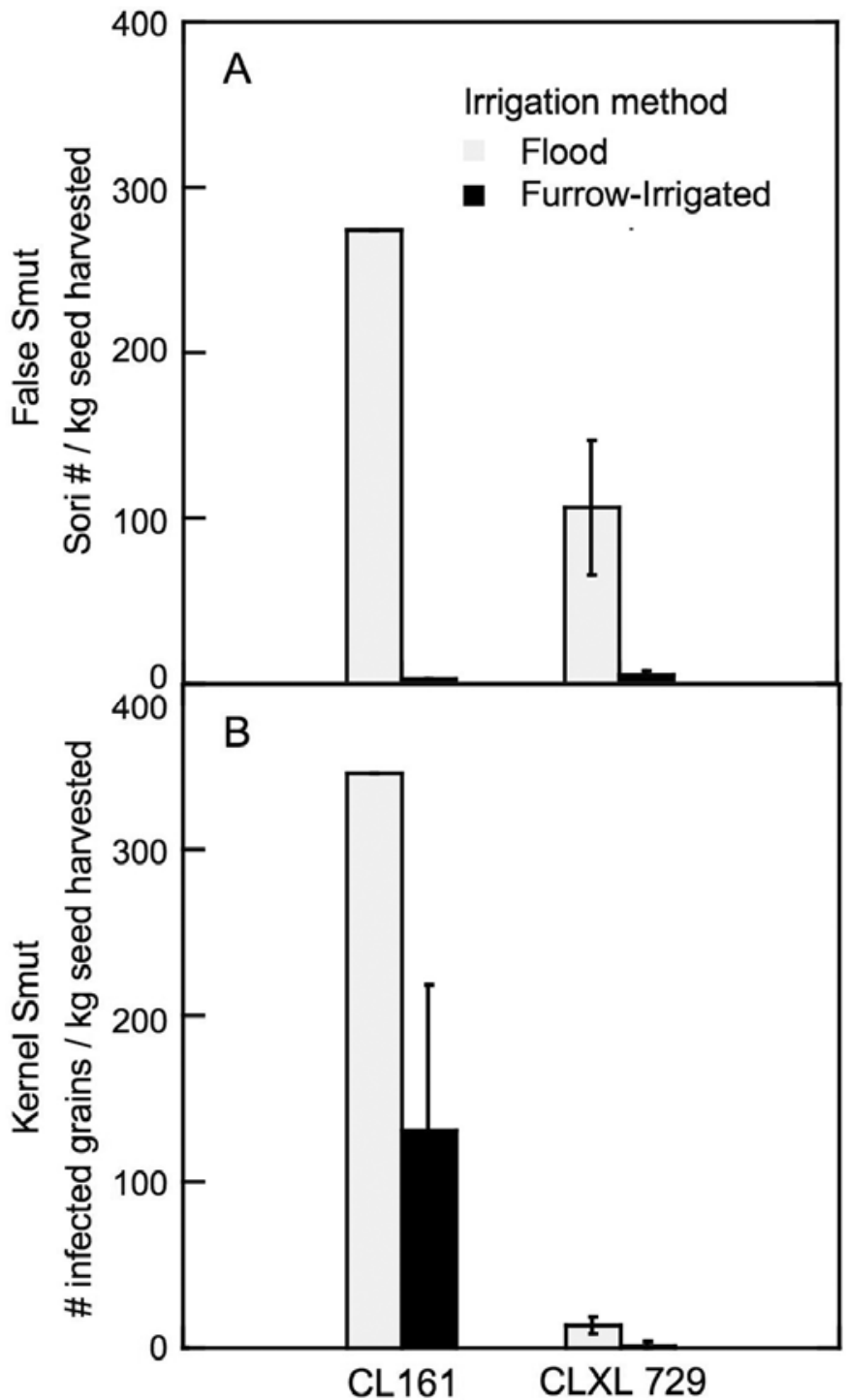

Fig. 2. Smut severities shown as mean number of infected kernels per kilogram of harvested rice seed (Y-axes) for rice entries CL161 and CLXL 729 (X-axis) included in the 2008 smut nursery. A, False smut and $\mathbf{B}$, kernel smut severities are plotted for both entries in flooded (gray bars) and furrowirrigated (black bars) conditions.

CLXL 729 used in the prior two experiments. False smut observations for CLXL 729 were similar to the aforementioned studies, and furrow irrigation reduced false smut severity by $96 \%$ compared to flooded plots (Fig. 2A). Similarly, a 99\% reduction in false smut severity was observed for CL161. Kernel smut severity in CLXL 729 (resistant) was also low in this experiment (Fig. 2B). A small difference in kernel smut severity between furrow-irrigated and flooded conditions was observed, but it was negligible in magnitude due to the overall low levels of disease. Kernel smut severity was high in CL161 (susceptible), in both flooded and furrow-irrigated plots. Limitations encountered in this single-year study (see methods) rendered it impossible to determine if the observed differences in kernel smut severity in CL161 were significant.

Canopy temperature and relative humidity were recorded in flooded and furrowirrigated plots of CLXL 729 for 3 weeks during the 2008 smut nursery flowering period (Table 2). Average daily temperatures and average daytime high temperatures were greatest in the flooded plots. The canopy relative humidity (daily average and during the daytime high temperature period) was also highest in the flooded plots. However, differences in daily temperature and relative humidity were negligible in magnitude $\left(1.24^{\circ} \mathrm{C}\right.$ and $2.91 \%$, respectively) compared to the daily fluctuation range. The daily temperature fluctuation was $9.74^{\circ} \mathrm{C}$ in furrow-irrigated plots and $10.54^{\circ} \mathrm{C}$ in flooded plots. The daily relative humidity fluctuation was $25.22 \%$ in furrow-irrigated plots and $24.24 \%$ in flooded plots. The similarity of daily fluctuations between flooded and furrow-irrigated plots is evident in the overlap of value ranges observed for each measure (Table 2).

\section{DISCUSSION}

False smut is emerging as a disease of importance for rice production worldwide $(12,14,16)$. Observations on the annual severity and extent of distribution of the disease are nonexistent, presumably due to a lack of research focus in those areas and the relatively recent development of the

Table 2. Canopy temperature and relative humidity (RH) comparisons between flooded and furrow-irrigated rice in the 2008 disease nursery ( 28 July to 17 August 2008)

\begin{tabular}{lcl}
\hline Temperature $\left({ }^{\circ} \mathbf{C}\right)$ & $\mathbf{R H}(\%)$ & \multicolumn{1}{c}{ Measurement } \\
\hline 1.24 & $\ldots$ & Degrees warmer in flood irrigation total day length (8:00 A.M. to 7:00 P.M.) \\
$\ldots$ & 2.91 & Percent more humid in flood irrigation total day length (8:00 A.M. to 7:00 P.M.) \\
31.59 & $\ldots$ & Average temperature from noon to 2:00 P.M. in furrow irrigation \\
33.39 & $\ldots$ & Average temperature from noon to 2:00 P.M. in flood irrigation \\
1.80 & $\ldots$ & Difference in average daytime high temperature, degrees warmer in flood irrigation \\
$\ldots$ & 71.08 & Average RH between noon and 2:00 P.M. in furrow irrigation \\
$\ldots$ & 2.30 & Average RH between noon and 2:00 P.M. in flood irrigation \\
$\ldots$ & $\ldots$ & Difference in average daytime RH, percent more humid in flood irrigation \\
$21.89-31.63$ & $\ldots$ & Daily temperature range, average in furrow irrigation at 6:00 A.M. and 1:00 P.M. \\
$23.03-33.57$ & $69.06-94.28$ & Daily temperature range, average in flood irrigation at 6:00 A.M. and 1:00 P.M. \\
$\ldots$ & $69.95-94.19$ & Daily RH range, average RH in furrow irrigation at 1:00 P.M. and 6:00 A.M. \\
$\ldots$ & & Daily RH range, average RH in flood irrigation at 1:00 P.M. and 6:00 A.M. \\
\hline
\end{tabular}


disease's importance. Anecdotal reports (S. A. Brooks, personal communications) suggest that the disease is most severe on late-planted rice, but it is not known if variability in disease severity is due to normal annual climatic variation or favorable environmental factors late in the growth season. Interestingly, the highest levels of disease reported herein were in late-planted rice. The 2006 irrigation experiment was planted 1 month later than the two subsequent years and also had the highest levels of disease. Similarly, in 2008 an independent disease nursery was planted 5 days prior to the smut nursery of this report. The nursery also contained CLXL 729 as an entry, under flood irrigation, with an identical fertility treatment. The 5-day-earlier planting (and 11-day-earlier heading) resulted in CLXL 729 escaping the disease (not shown). Additional field observations from 2008 clearly showed a false smut outbreak on late-planted rice. However, we cannot determine if this is coincident with the observations of others, or if false smut severity and favorable late-season conditions are truly linked.

Previously (2), we reported a higher incidence of false smut in rice grown in rotation with soybean than in continuous rice cultivation. This apparent contradiction between studies, where the same rotation treatment was significant in our previous work but not in the current report, is likely due to the length of time in rotation. Results in our previous report (2) were from years six and seven of a long-term crop rotation study. The present report is based upon years one through three of our irrigation studies. Since we consider the effect from rotation to be caused by soil $\mathrm{N}$ accumulation due to nitrogen fixation from the soybean crop (2), it is likely that the current study has not been in place long enough for rotation to become a significant treatment.

Variations in false smut severity over years, planting dates, or experimental treatments did not occur in furrowirrigated rice. In this case, false smut severity was consistently low in all field experiments, conducted over 3 years, with three susceptible rice varieties and multiple fertility treatments. The furrow irrigation treatment nearly eliminated false smut from susceptible hybrid and inbred varieties, demonstrating that the phenomenon was not unique to an individual variety. Furrow irrigation also confounded the fertilizer treatment that was known to positively influence the disease in flooded conditions (2). Either the effect of furrow irrigation negated the effect of fertilizer treatments or the switch to aerobic soil conditions altered the plant physiology such that fertility had no effect. Our current data support both options. In favor of the former, the near elimination of false smut disease in all furrow-irrigated rice plots precludes the resolution of additional treatments. For the latter, $\mathrm{N}$ rate positively influenced yield in furrow-irrigated rice, demonstrating that fertility treatments were effective, but did not influence false smut.

Dissimilarity of plot microclimates is another option that could explain the differences in false smut severity between the two irrigation treatments. Our results can likely rule out this option. Canopy microclimate measurements made in 2008 indicate that the differences observed in temperature and relative humidity were negligible compared to the daily fluctuations that occur. Furthermore, furrow irrigation did not reduce kernel smut severity in the susceptible rice cultivar CL161, demonstrating that environmental conditions in the nonflooded rice canopy had no effect on this disease, and that the ricefalse smut phenomenon is unique to that host-pathogen system.

The effect of furrow irrigation on false smut severity is interesting beyond the scope of its utility for establishing "field resistance" to false smut. This observation is contradictory to the effect of furrow irrigation on blast disease (Pyricularia grisea (Cooke) Sacc.) of rice. It is known that nonflooded conditions favor blast by imposing a physiological stress on the host plant (14). This dichotomy supports the hypothesis that there is a physiological change in the host plant effecting false smut susceptibility, as we do not expect water-stressed rice plants to increase tolerance to one disease and not another. Although this system will help elucidate the mechanisms of susceptibility to false smut, caution must be used with field implementation as furrow-irrigated rice could develop severe blast disease. To this end, hybrids appear to be the best option for field implementation. Some hybrids are blast resistant (13), and blast symptoms were negligible on hybrid entries in these experiments.

We can only speculate about the mechanism of false smut suppression in furrowirrigated rice. It seems likely that the physiological change in the host plant in response to the shift from anaerobic (flooded) to aerobic (furrow-irrigated) growing conditions was also responsible for suppression of false smut symptoms. Our primary consideration for future research is determining whether or not furrow-irrigated rice becomes infected with $U$. virens and sporulation is suppressed, or if the infection process itself is hindered. Regardless of the mechanism, the dramatic reduction in sporulation of false smut represents a strategy for disease control through reduction in the annual accumulation of pathogen chlamydospores and pseudomorphs in the soil.

\section{ACKNOWLEDGMENTS}

The authors would like to recognize the contributions of the following people to this project:
Aaron Jackson, Fleet Lee, Danny McCarty, Anna McClung, Gordon Miller, Tara Moss, Brian Ottis, Terry Sells, James Stroike, and Kazuyo Ueda. We also extend our thanks to RiceTec, Inc. for providing seed and financial support for this project.

\section{LITERATURE CITED}

1. Bouwman, A. F. 1991. Agronomic aspects of wetland rice cultivation and associated methane emissions. Biogeochemistry 15:65-88.

2. Brooks, S. A., Anders, M. M., and Yeater, K. M. 2009. Effect of cultural management practices on the severity of false smut and kernel smut of rice. Plant Dis. 93:1202-1208.

3. Cartwright, R. D., Lee, F. N., Chlapecka, R. M., and Vann, S. R. 1998. First report of false smut of rice in Arkansas. (Abstr.) Proc. 30th Annu. RTWG Meet. Reno, NV.

4. Cicerone, R. J., and Delwiche, C. C. 1993 Factors effecting methane production under rice. Global Biogeochem. Cy. 7:143-155.

5. Datnoff, L. E. 1994. Influence of mineral nutrition of rice on disease development. Pages 89-100 in: Rice Pest Science and Management P. S. Teng, K. L. Heong, and K. Moody, eds. International Rice Research Institute, Los Baños, Phillipines.

6. Gillip, J. A., and Czarnecki, J. B. 2009. Validation of a ground-water flow model of the Mississippi river valley alluvial aquifer using water-level and water-use data for 1998-2005 and evaluation of water use scenarios. U.S. Geol. Survey Sci. Invest. Rep. 2009-5040.

7. Lee, F. N., Templeton, G. E., Cartwright, R D., Long, D. H., and Hornbeck, J. M. 1992 Pathogenicity of Tilletia barclayana isolates. Pages 81-85 in: Arkansas Rice Research Studies 1992. B. R. Wells, ed. Res. Ser. 422. Ark Agric. Exp. Stn. Fayetteville.

8. Leung, H., Zhu, Y., Revilla-Molina, I., Fan, J. X., Chen, H., Pangga, I., Vera Cruz, C., and Mew, T. W. 2003. Using genetic diversity to achieve sustainable rice disease management. Plant Dis. 87:1156-1169.

9. Olk, D. C., Anders, M. M., Filley, T. R., and Isbell, C. 2009. Crop nitrogen uptake and soil phenols accumulation under continuous rice cropping in Arkansas. Soil Sci. Soc. Am. J. 73:952-960.

10. Reed, T. B. 2003. Recalibration of a groundwater flow model of the Mississippi river valley alluvial aquifer of northeastern Arkansas, 1918-1998, with simulations of water levels caused by projected ground-water withdrawals through 2049. U.S. Geol. Survey Water Resources Invest. Rep. 03-4109.

11. Rush, M. C., Shahjahan, A. K. M., Jones, J. P., and Groth, D. E. 2000. Outbreak of false smut of rice in Louisiana. Plant Dis. 84:100.

12. Tsuda, M., Sasahara, M., Ohara, T., and Kato, S. 2006. Optimal application timing of simeconazole granules for control of rice kernel smut and false smut. J. Gen. Plant Pathol. 72:301-304.

13. University of Arkansas. 2007. Arkansas rice performance trials, 2005-2007. In: Rice Information, No. 166, December 2007. University of Arkansas, Stuttgart.

14. Webster, R. K., and Gunnell, P. S. 1992. Compendium of Rice Diseases. American Phytopathological Society, St. Paul, MN.

15. Wilson, C. E., Jr., and Branson, J. W. 2006 Trends in Arkansas rice production. Pages 1726 in: Rice Research Studies 2005. B. R Wells, ed. Res. Ser. 540. Ark. Agric. Exp. Stn. Fayetteville.

16. Zhou, Y.-L., Pan, Y.-J., Xie, X.-W., Zhu, L.-H., Wang, S., and Li, Z.-K. 2008. Genetic diversity of rice false smut fungus, Ustilaginoidea virens and its pronounced differentiation of populations in north China. J. Phytopathol. 156:559-564. 